\title{
Carnets
}

Revue électronique d'études françaises de l'APEF

Première Série - 1 Numéro Spécial | 2009

Cultures littéraires : nouvelles performances \& développement

\section{A hipermédia como síntese interactiva dos discursos digitais}

\section{Pedro Barbosa}

\section{(2) OpenEdition}

\section{Journals}

\section{Edição electrónica}

URL: http://journals.openedition.org/carnets/3949

DOI: 10.4000/carnets.3949

ISSN: 1646-7698

Editora

APEF

Edição impressa

Data de publição: 1 junho 2009

Paginação: 267-270

\section{Refêrencia eletrónica}

Pedro Barbosa, «A hipermédia como síntese interactiva dos discursos digitais », Carnets [Online] Première Série - 1 Numéro Spécial | 2009, posto online no dia 16 junho 2018, consultado o 24 setembro 2020. URL : http://journals.openedition.org/carnets/3949 ; DOI : https://doi.org/10.4000/ carnets.3949

Carnets est mis à disposition selon les termes de la licence Creative Commons - Atribution - Pas d'utilisation commerciale 4.0 International. 


\title{
A HIPERMÉDIA COMO SÍNTESE INTERACTIVA DOS DISCURSOS DIGITAIS
}

Pedro Barbosa, PhD

(CETIC, NUPh, CERTEL, CECL)

\begin{abstract}
Resumo
Apresentação e discussão do projecto hipermediático «Alletsator/Rotastella» como pretexto para a discussão das novas textualidades digitais na era da informática - sua repercussão na redefinição do conceito de Literatura e suas margens.

Tendo em conta que este projecto, hoje um projecto colaborativo entre dois centros de pesquisa em Portugal e no Brasil (CETIC e NUPh), arrancou de um projecto de literatura generativa exclusivamente verbal (materializado no Sintext de 1995 e depois em «O Motor Textual», 2001), tendo posteriormente migrado para o palco teatral em 2001 com a ópera electrónica «AlletsatorXPTO.kosmos.2001» (aquando da Porto Capital Europeia da Cultura), e estando numa terceira fase a ser recriado em ambientes 3D virtuais integrados numa estrutura hipermédia, a reflexão que se propõe tentará dar uma ideia desta migração discursiva nas suas 3 etapas: literária, teatral, hipermedia.
\end{abstract}

Palavras-chave: projecto hipermediático «Alletsator/Rotastella», literatura generativa Keywords: Hypermedia Project «Alletsator/Rotastella»; Generative Literature 
1) A etapa literária como texto automático virtual no sintetizador textual «Sintext»: http://www.pedrobarbosa.net/SINTEXT-pagpessoal/SINTEXT.HTM

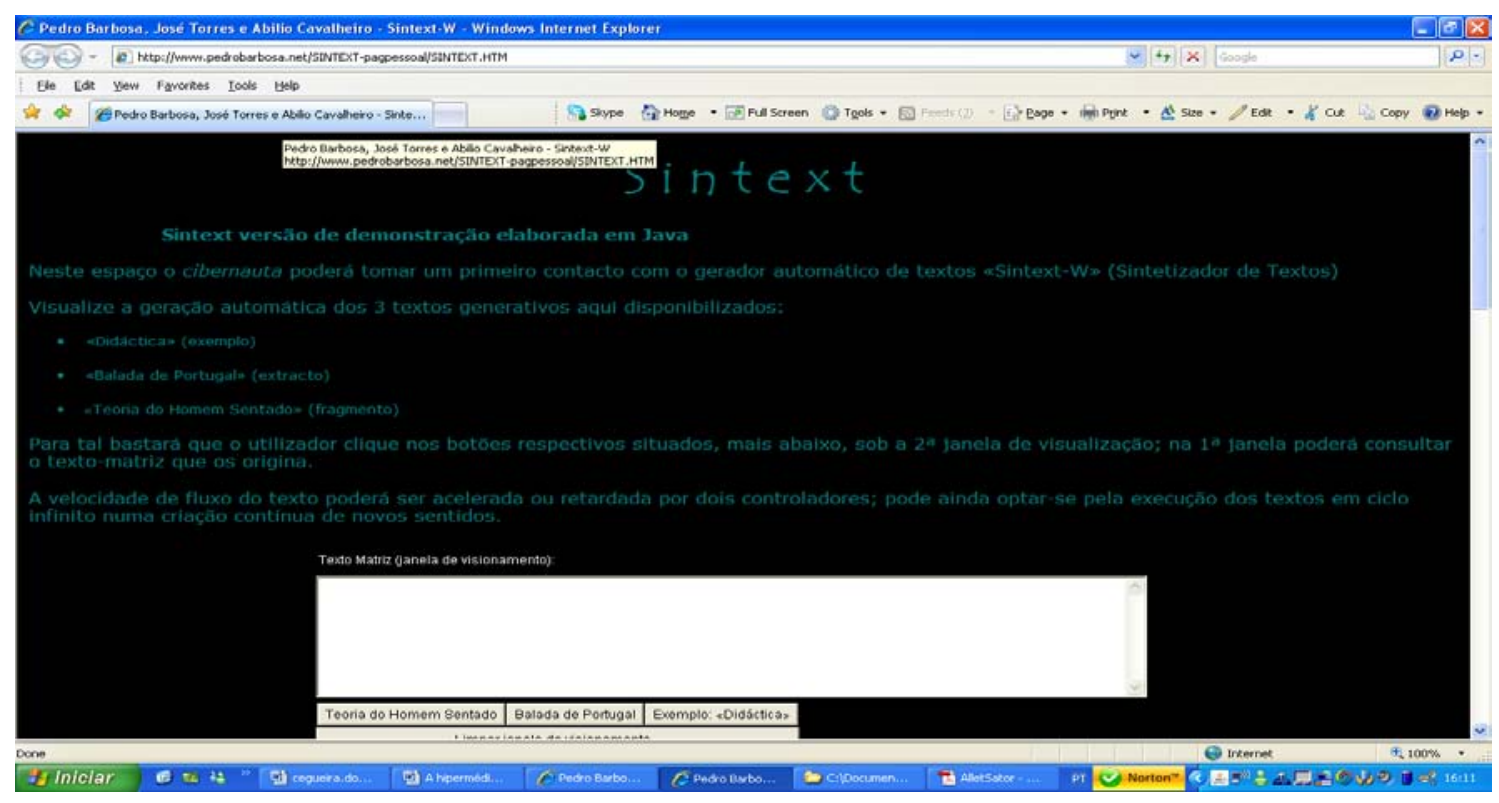

2) A etapa teatral materializada num discurso linear que fixa uma solução dramatúrgica no âmbito da infinita multiplicidade de textos possíveis:

http://pedrobarbosa.net/alletsator-web/alletsator-web-molduraf.htm

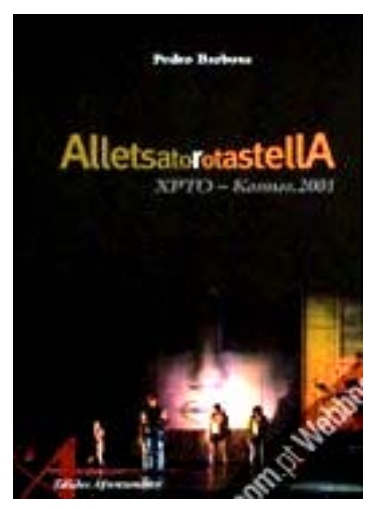

3) A etapa hipermédia que integra a cooperação semiótica da multiplicidade dos discursos digitais (imagem, som, palavra) promovendo a integração dos múltiplos recursos das novas textualidades nascidas com o advento da informática (imagem de síntese, som electrónico, texto automático, generatividade, hipertextualidade, multimédia, interactividade, etc.).

http://www.telepoesis.net/alletsator/ e http://www.pucsp.br/alletsator/ 


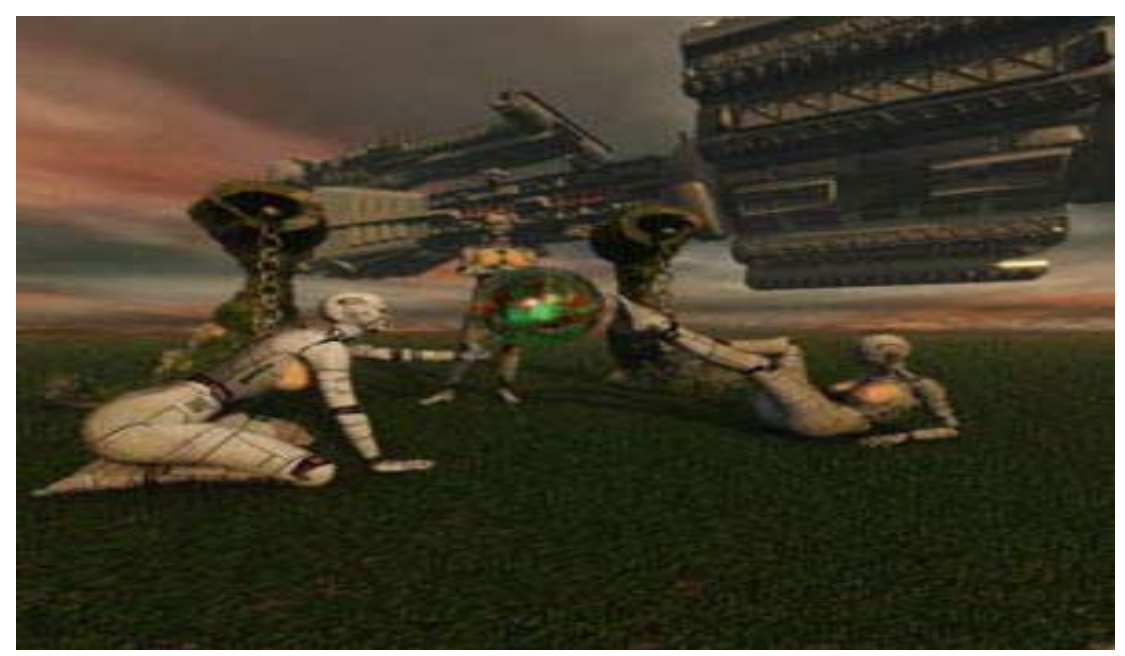

\section{AlletSator e o campo da pesquisa acadêmica em hipermídia}

por Luís Carlos Petry

PUC-SP

\section{:: Introdução}

Alletsator se constitui em uma ópera em formato hipermédia que, para os seus autores, melhor se define como uma ópera quântica, enfim um jogo - interactivo, tridimensional onde 0 actual e o virtual se entrecruzam e misturam. Um híbrido hipermédia, portanto, no qual se desafia o "espectactor" (imerso num ambiente que se pretende cósmico, mágico, fantástico, onírico...) a percorrer a superfície de uma sequencialidade por si próprio traçada. Uma viagem sem fim, pois trata-se de uma narrativa em rede gerada por uma interface que permite combinações potencialmente infinitas. Da dramaturgia que lhe serve de base antecipava-se já a metáfora que melhor explica este trabalho: uma nave espacial de caminhos dispersos, de inesperados percursos multilineares em potência. «Alletsator» é também um objecto artístico dos novos meios, produto e agente de uma cibercultura que promete revolucionar o mundo tal como o conhecemos.

Inicialmente, o texto da peça de teatro computacional Alletsator foi gerado automaticamente por Pedro Barbosa (do NuCIT : ESMAE-Escola Superior de Música e das Artes do Espectáculo) no sintetizador textual «Sintext» e trabalhado dramaturgicamente para um espectáculo teatral do Esbofeteatro que foi apresentado no Teatro Helena Sá e Costa, aquando dos eventos da Porto Capital Europeia da Cultura em 2001, com encenação de João Paulo Costa e música electrônica de Virgílio Melo. 0 libreto operático de Pedro Barbosa encontra-se publicado pelas edições Afrontamento com o título inicial: «AlletSator-XPTO.Kosmos.2001». Foi a partir desse texto concebido como uma experiência pioneira de "ciberdramaturgia", que Luís Carlos Petry, professor e investigador da PUC em São Paulo (do Programa de Pós-graduação em Tecnologias da Inteligência e Design Digital - TIDD), se propôs transpôs a narrativa teatral a uma 
hipermédia interactiva e, desde então, passou a colaborar com Pedro Barbosa na sua roteirização e recriação para um ambiente 3D e uma estrutura narrativa em rede.

Se incialmente as versões de AlletSator (em número de três), eram destinadas ao seu uso em DVD-Rom, a atual versão 4.0 da Ópera Quântica encontra-se em fase de produção para ser utilizada na WEB, dentro da tecnologia de programação de autoria Macromedia Shockwave.

:: Projecto colaborativo - Portugal/Brasil

Para mais informações sobre o projecto, poderão ser pesquisados na Internet os seguintes portais:

http://www.telepoesis.net/alletsator/wiki/index.php?title=AlletSator

Portal português:

http://www.telepoesis.net/alletsator/

Portal brasileiro:

http://www.pucsp.br/alletsator/ 